\title{
RESENHA: Treinamento, desenvolvimento e educação: Tendências no estilo de gestão das organizações
}

\author{
Thaís Zerbini \\ Universidade de São Paulo, Ribeirão Preto-SP, Brasil
}

Borges-Andrade, J. E., Abbad, G., \& Mourão, L. (Orgs.). (2006). Treinamento, desenvolvimento e educação em organizações e trabalho: Fundamentos para a gestão de pessoas. Porto Alegre: Artmed.

A leitura do livro organizado por Jairo Eduardo Borges-Andrade, Gardênia da Silva Abbad e Luciana Mourão é altamente recomendável para estudantes, pesquisadores e profissionais de Psicologia Organizacional e do Trabalho (POT) que pretendem atuar ou atuam na área de Treinamento, Desenvolvimento e Educação (TD\&E) nas organizações e em contextos de trabalho diversos.

Atualmente, $o$ atendimento às novas exigências do mercado de trabalho, caracterizado por transformações sociais e tecnológicas, exige que empresas, escolas técnicas, órgãos de governo, entre outras instituições que compõem o sistema produtivo, desenvolvam estratégias de atualização contínua de suas competências organizacionais e individuais. É fato também, que um dos grandes desafios do Brasil é promover o desenvolvimento sustentável econômico e social em diversas regiões. Programas de TD\&E nas empresas e de formação e qualificação profissional em ambiente aberto contribuem para que este desenvolvimento ocorra. Eduardo Salas, pesquisador renomado da área, Ph.D. pela University of Central Florida, destacou no prefácio do livro esta necessidade: "As organizações sabem que, para serem viáveis e competitivas nesta 'planície', elas precisam ser coleções de habilidades adaptáveis em sua força de trabalho e ter empregados, executivos e gestores com conhecimentos e habilidades atualizados." (p.11).

As organizações, preocupadas com a manutenção da competitividade no mercado, mostramse interessadas em entender como ocorrem os processos de aprendizagem e, principalmente, os processos de transferência para os diferentes níveis da organização. Torna-se necessário entender, portanto, como ocorrem tais processos em diferentes ambientes corporativos e profissionais. Para possibilitar o estudo desses fenômenos, pesquisadores e profissionais precisam identificar formas de garantir a melhoria do desempenho no trabalho, investigando o processo de aquisição de conhecimentos, habilidades e atitudes (CHA's) por meio de ações de TD\&E, formação e qualificação profissional. Neste sentido, o livro é um grande auxílio para o profissional de TD\&E que precisa exercer seu trabalho de pesquisa e intervenção em contexto de organizações e trabalho.

O livro é composto por vinte e nove capítulos distribuídos em quatro partes, a saber: Parte I Contexto e desafios em TD\&E; Parte II - Avaliação de necessidades e delineamento de soluções em TD\&E; Parte III - Avaliação dos sistemas de TD\&E; e Parte IV - TD\&E em organizações e trabalho: casos. A estrutura dos capítulos é padronizada e desenvolvida em cinco seções. No início do capítulo são apresentados os objetivos de aprendizagem que o leitor deverá alcançar ao final da leitura. Em seguida, há uma breve seção introdutória que apresenta a proposta do capítulo e seus conteúdos. A terceira seção consiste na revisão e análise da literatura desenvolvida nas três últimas décadas, na qual são apresentados e discutidos conceitos, definições, resultados de pesquisa e exemplos de instrumentos de medida sobre o tema. Na quarta seção considerações finais - retomam-se os objetivos do 
capítulo, faz-se uma análise crítica da revisão de literatura apresentada e discutem-se as tendências teóricas e práticas sobre o tema. E, ao final do capítulo, o leitor é presenteado com pertinentes questões para discussão.

O referencial teórico utilizado na maioria das pesquisas nacionais e estrangeiras sobre ações de TD\&E segue a abordagem sistêmica. Os elementos que compõem o sistema de TD\&E são: avaliação de necessidades, planejamento e execução, e avaliação, sendo que esses mantêm entre si trocas constantes de informações e resultados. O subsistema avaliação de necessidades de treinamento identifica as competências necessárias que uma organização precisa desenvolver para alcançar seus objetivos, os CHA's que um indivíduo deve apresentar para desempenhar sua função, bem como, identifica os indivíduos que necessitam de treinamento por não apresentarem esses CHA's desenvolvidos. Em seguida, a ação educacional é planejada e executada a partir da definição dos objetivos instrucionais, definição do conteúdo, da sequiência do ensino e da escolha dos meios e estratégias instrucionais mais adequados para se alcançar os objetivos descritos. Por fim, a avaliação de treinamento fornece ao sistema informações sistemáticas sobre lacunas no desempenho dos indivíduos e dos instrutores, identifica falhas no planejamento de procedimentos instrucionais, indica se o treinamento foi positivo para os indivíduos e organizações em termos de aplicabilidade e utilidade, informa o quanto as habilidades aprendidas estão sendo aplicadas no trabalho ou na vida profissional dos indivíduos e quais aspectos facilitam ou dificultam este processo (Borges-Andrade, 1997).

O livro, após uma contextualização, segue a mesma sequiência do sistema de TD\&E. Os capítulos iniciais que compõem a Parte I demarcam o contexto no qual o livro está inserido: organizações, trabalho, aprendizagem e ações de TD\&E. Relações entre a reestruturação produtiva e a qualificação do trabalhador, importância e necessidade de programas de formação profissional, relação de práticas inovadoras em gestão de pessoas com aprendizagem nas organizações, bem como história, importância e conceitos relacionados ao sistema de TD\&E são os assuntos abordados. $\mathrm{O}$ último capítulo da primeira parte do livro, escrito por Jairo Eduardo BorgesAndrade, discute um aspecto fundamental da área: a competência política que o profissional de TD\&E precisa desenvolver para atuar de forma estratégica em uma organização. Zanelli e Bastos (2004) discutem a mesma problemática no livro Psicologia, Organizações e Trabalho no Brasil, referência nacional em temas relacionados à área de POT. Ao longo da discussão, fica evidente a preocupação quanto à formação dos estudantes de graduação e dos profissionais da área. Segundo os autores, nos anos de 1980, o Conselho Federal de Psicologia verificou que a atuação da maioria dos psicólogos apresentava um forte viés tecnicista, com a utilização de modelos e pacotes prontos para a solução de problemas. Além disso, o trabalho desenvolvido era fragmentado, sem visão estratégica e política de todo e de fim. Entretanto, com a ampliação dos mercados e com o aumento da competitividade, as organizações e a realidade de trabalho passaram a exigir novas posturas e formas de atuação do psicólogo organizacional e do trabalho. E é sobre esta nova postura que Borges-Andrade discute: o profissional deve atuar, não somente como técnico, mas como consultor, pesquisador e agente de mudanças.

Na Parte II, discute-se sobre o diagnóstico e o prognóstico de necessidades e a proposta de soluções para resolver os eventuais problemas de desempenho detectados, incluindo ações de TD\&E presenciais e a distância para suprir lacunas de competências. Em análise da literatura nacional e estrangeira, Abbad, Carvalho e Zerbini (2006) observaram que, na prática vigente, as organizações não utilizam avaliações sistemáticas de necessidades de treinamento, não as relacionam às competências organizacionais ou as alinham às estratégias organizacionais, fazem pequeno esforço de avaliação de aprendizagem e investem pouco em planejamento instrucional de cursos presenciais. Além disso, utilizam com mais frequiência treinamentos presenciais que privilegiam poucas pessoas da organização, em detrimento de treinamentos a distância que poderiam alcançar um número bem maior de participantes de diferentes 
unidades da organização. Segundo as referidas autoras a ampliação do acesso a treinamento, formação e qualificação profissionais vem sendo viabilizada pela aplicação das Novas Tecnologias de Informação e Comunicação (NTICs) em projetos de educação a distância. Os treinamentos mediados por NTICs, somadas às tecnologias tradicionais de disponibilização de conteúdos como o material impresso, materiais em vídeo e áudio, correspondência, vêm se tornando ferramentas fundamentais para capacitação e qualificação profissional dos trabalhadores. Todas estas tendências, relacionadas à educação corporativa e continuada, bem como à educação para o trabalhador, são discutidas nesta parte do livro.

No capítulo inicial da Parte III é apresentado um modelo teórico de avaliação e seus componentes: características da clientela, procedimentos instrucionais, processos, resultados imediatos (aprendizagem), elementos do contexto (necessidades, suporte, disseminação e efeitos no desempenho dos indivíduos e das organizações e retorno de investimentos). Nos capítulos seguintes, o modelo é desmembrado em seus componentes e a sua aplicabilidade no contexto de organizações e trabalho fica evidente por meio de relatos de pesquisas e instrumentos de medida validados de acordo com pressupostos estatísticos. Além disso, são discutidos diferentes delineamentos metodológicos, bem como problemas metodológicos relacionados à mensuração.

Fechando o livro, a Parte IV apresenta casos que relatam a aplicação do conhecimento apresentado nos capítulos anteriores em três diferentes contextos: uma instituição bancária, uma universidade e um hospital.

Para finalizar, deixo registrado que o livro é fruto de trabalho intenso e constante de um grupo de pesquisadores da área de POT e da Administração que integrou o Núcleo de Excelência "Treinamento e Comportamento no Trabalho", contemplado pelo Programa de Apoio a Núcleos de Excelência (PRONEX/CNPq), e foi coordenado por Jairo Borges-Andrade. O grupo, com aproximadamente cinqüenta integrantes, teve como sede a Universidade de Brasília e contou com a participação das
Universidades Federais da Bahia, de Minas Gerais e de Uberlândia. Sem dúvida, o trabalho dos organizadores do livro é um exemplo de profissionalismo e competência.

O livro Treinamento, desenvolvimento $e$ educação em organizações e trabalho se tornou uma referência da área, não só no Brasil, mas em toda a América Latina e, novamente cito um trecho do prefácio escrito por Eduardo Salas: "Ele é o único na América Latina para se compreender a ciência e a prática de aprendizagem e desenvolvimento. Tomara que venham outros.” (p.11). E virão. O mesmo grupo de pesquisadores iniciou as discussões para a organização de um livro de escalas construídas e validadas na área de avaliação de TD\&E presenciais e a distância. O projeto está previsto para 2009.

\section{Referências}

Abbad, G., Carvalho, R. S., \& Zerbini, T. (2006). Evasão em curso via internet: Explorando variáveis explicativas [Versão eletrônica]. Revista de administração de empresas eletrônica, 5(2), 126. Retirado em 10 julho 2006, de http:// w w w.ra e.com.br/e letronica/ index.cfm? FuseAction $=$ artig o \& ID $=3652$ $\&$ Secao $=$ ARTIGOS $\&$ Volume $=5 \&$ Numero $=2 \&$ Ano $=2006$

Borges-Andrade, J. E. (1997). Treinamento de pessoal: Em busca de conhecimento e tecnologia relevantes para as organizações brasileiras. In A. Tamayo, J. E. Borges-Andrade \& W. Codo (Orgs.), Trabalho, organizações e cultura (pp. 129-149). São Paulo: Cooperativa de Autores Associados.

Zanelli, J. C., \& Bastos, A. V. B. (2004). Inserção profissional do psicólogo em organizações e no trabalho. In J. C. Zanelli, J. E. Borges-Andrade \& A. V. B. Bastos (Orgs.), Psicologia, organizações e trabalho no Brasil (pp. 466-491). Porto Alegre: Artmed.

Resenha recebida em 07/10/2007. Aceita para publicação em 25/03/2008. 
Endereço para correspondência:

Thaís Zerbini. Departamento de Psicologia e Educação. Faculdade de Filosofia, Ciências e Letras de Ribeirão Preto. Universidade de São Paulo. Av. Bandeirantes, 3900. CEP: 14040-901. Ribeirão PretoSP, Brasil. E-mail: thais.zerbini@gmail.com

Thaís Zerbini é Professor Doutor da Faculdade de Filosofia, Ciências e Letras de Ribeirão Preto da Universidade de São Paulo. 